\title{
Antithrombin III and fibrinogen degradation product (fragment E) in diabetic nephropathy
}

\author{
VIVIAN CHAN, CK YEUNG, TK CHAN \\ From the Department of Medicine, University of Hong Kong, Queen Mary Hospital, Hong Kong
}

SUMmARY Plasma antithrombin III (AtIII), serum fragment E (FgE) and urine AtIII and FgE were measured in 25 diabetic patients with proteinuria above $1 \mathrm{~g}$ per day and compared to that in 25 patients with non-diabetic nephropathy, matched for the degree of proteinuria. Plasma AtIII concentrations were normal in both groups but FgE concentrations were increased. The level of plasma AtIII was directly related to $\mathrm{HbA}_{1}$ concentrations in the diabetics. For the same degree of proteinuria, the diabetic patients lost more AtIII and FgE in the urine. Urine AtIII was found to be mostly bound to activated procoagulants. Both urine AtIII and urine FgE correlated inversely with creatinine clearance. It was concluded that intraglomerular thrombosis probably contributes to the deteriorating renal function in diabetic nephropathy and is reflected in the concentrations of urine AtIII and FgE.

Diabetic nephropathy accounts for approximately $6 \%$ of all deaths among patients with maturityonset diabetes mellitus and $20 \%$ of the insulindependent type, but despite extensive studies of the pathological changes and clinical features, its pathogenesis remains controversial and thus treatment and prevention unsatisfactory. ${ }^{1}$ Although the primary defect in diabetic glomerulosclerosis lies in the vessel wall ${ }^{2}$ with basement membrane thickening and increased vascular permeability, the coagulation mechanism might play an intermediary role as mediator of further glomerular vascular injury. Recently, antithrombin III (AtIII), the major modulator of intravascular thrombosis is found to be strategically located in the glomerular tuft, Bowman's capsule and the vessel wall $^{3}$ and synthesised by the endothelial cells lining the vasculature. ${ }^{4}$ In view of this, we studied plasma and urine AtIII concentrations in patients with diabetic nephropathy to define the pattern of change associated with progression of the disease. In addition, diabetic glomerulosclerosis is associated with increased fibrin deposition in the endothelial and mesangial regions ${ }^{5} 6$ and this would be reflected by an increase in fibrinogen degradation products (FDP). Thus one of the FDP, fragment $\mathrm{E}(\mathrm{FgE})$, was also monitored in serum and urine.

It is known that the occurrence and progression of nephropathy vary unpredictably in diabetic

Accepted for publication 16 November 1981 patients. ${ }^{7} 8$ Takazakura et $a l^{9}$ have shown that progression cannot be predicted even with repeated renal biopsy. Jones et $a^{10}$ showed that serial monitoring of the inverse of serum creatinine reflected the progression of nephropathy and Viberti et $a^{11}$ suggested that serum $\beta_{2}$-microglobulin concentration may be a more sensitive index. If AtIII and FgE concentrations were related to the progression of nephropathy, monitoring of their changes could provide sensitive indices of deteriorating renal function.

\section{Patients and methods}

Two groups of patients were studied. Group A consisted of 25 diabetic patients (11 women and 14 men) with proteinuria of greater than $1 \mathrm{~g} /$ day. They were aged 29-81 yr (median 61.5 yr, mean 60.9 \pm 9.6 yr). All but one, had diabetes mellitus beginning after the age of $40 \mathrm{yr}$ and have been followed in our diabetic clinic for 1-23 yr (median 9.1 yr, mean 9.37 \pm $5.9 \mathrm{yr}$ ). At the time of this study, 14 were receiving insulin and 11 receiving oral hypoglycaemic agent (gliclazide or glibenclamide). Group B consisted of 25 non-diabetic patients ( 11 women and 14 men), who were matched with group A patients for the same degree of proteinuria. They were aged 16-61 (median $38.5 \mathrm{yr}$, mean $39.1 \pm 12.7 \mathrm{yr}$ ). None of the patients had any clinical evidence or past history of venous thromboembolism.

In the diabetic patients, retinopathy assessed by 
opthalmoscopy and retinophotography was found to be severe in five, moderate in four, mild in eight and absent in eight. No renal biopsy was performed in any of these patients.

In the non-diabetic patients, 17 had primary glomerulonephritis and histopathology showed seven with membranous changes, six with focal sclerosing changes, three with diffuse proliferative changes and one with minimal change. The remaining patients consisted of four with chronic tubulointerstitial nephritis, two with systemic lupus erythematosus, one with benign nephrosclerosis and one with malignant essential hypertension.

All the patients were admitted into the metabolic unit to enable accurate collection of 24-hour urine for AtIII, FgE, protein and creatinine. In addition citrated plasma obtained from nine parts of blood added to one part $3.8 \%$ sodium citrate was used for the determination of AtIII. Serum obtained from blood added to $\epsilon$-aminocaproic acid $(1 / 20$ the volume of $1 M$ EACA) and allowed to clot overnight at $4^{\circ} \mathrm{C}$ was used for the determination of $\mathrm{FgE}$. Serum was used for the quantification of albumin and creatinine and blood in EDTA for total haemoglobin $\mathrm{A}_{1}\left(\mathrm{HbA}_{1}\right)$ level.

Plasma and urine AtIII were measured immunologically by a specific radioimmunoassay (RIA) as described previously. ${ }^{12}$ Serum and urine FgE were measured by the RIA method of Gordon et al ${ }^{13}$ with minor modifications which increased the sensitivity tenfold. ${ }^{14}$ Serial doubling dilutions of all samples were made in each AtIII and FgE estimation. Protein and albumin were determined by the Lowry technique ${ }^{15}$ and creatinine concentrations measured on the Technicon Autoanalyzer. Total $\mathrm{HbA}_{1}$ was determined by affinity chromatography using the method of Gabbay et al. ${ }^{16}$

Urine from a diabetic patient with heavy proteinuria ( $3 \mathrm{~g} /$ day) was concentrated twentyfold by ultrafiltration (Amicon) and AtIII crossed immunoelectrophoretic (CIE) pattern determined as described previously. ${ }^{17}$

In addition, plasma AtIII concentrations were determined in 52 diabetic patients with minimal $(<100 \mathrm{mg} /$ day) or no proteinuria, of whom 28 have no retinopathy and 24 have background retinopathy.

Statistical analyses of results were made by linear regression using the least square method and comparisons by Student's paired and unpaired $t$ tests.

\section{Results}

SPECIFICITY OF RIA FOR ATIII AND FGE The standard curve of AtIII RIA for serum and urine samples is shown in Fig. 1a. The AtIII standards used (NIBSC 75/564) ranged from 0.25-8 $\mu \mathrm{g} / \mathrm{ml}$ and serial doubling dilutions of both plasma and urine samples from two patients showed parallel inhibitions to this standard curve, indicating the specificity of antiserum for human AtIII present in plasma and urine.

Similarly, serial dilutions of serum and urine samples from the same patients gave parallel inhibitions with the FgE standards (kindly provided by $\operatorname{Dr}$ Y Gordon, Royal Free Hospital, London) (Fig. 1b).

The recovery of AtIII added to four normal urine samples assayed fresh, after storage at room temperature for $24 \mathrm{~h}$ or after storage for $24 \mathrm{~h}$ at $4{ }^{\circ} \mathrm{C}$ were $90 \cdot 2 \pm 2 \cdot 2,90 \cdot 3 \pm 2 \cdot 0$ and $86.7 \pm 3.9 \%$ (mean \pm $\mathrm{SD})$ respectively and that for $\mathrm{FgE}$ were $90 \cdot 5 \pm 2 \cdot 4$, $87 \cdot 6 \pm 2 \cdot 1$, and $89 \cdot 3 \pm 2 \cdot 2 \%$ respectively.

\section{PATIENT DATA}

The biochemical data of the patients are shown in the Table. The mean age of the diabetic group was

Biochemical data in diabetic and non-diabetic groups (means $\pm S D)$

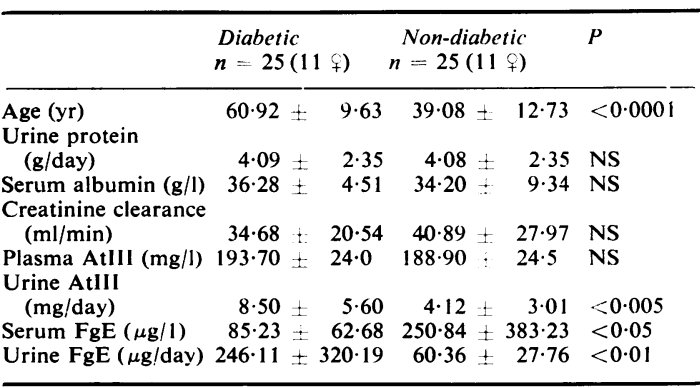

NS $=$ not significant.

$60 \cdot 9 \pm 9 \cdot 6$ (mean \pm SD) which was significantly higher than the non-diabetic group (mean age \pm SD $=39 \cdot 1 \pm 12 \cdot 7)$. Both groups were matched for the degree of proteinuria. Their glomerular filtration rates (GFR) measured by creatinine clearance and their serum albumin concentrations were similar.

In the diabetic patients, mean total $\mathrm{HbA}_{1}$ concentration was $12.66 \pm 2.23 \%$ compared to a mean of $8.16 \pm 0.94 \%$ in 21 normal subjects.

\section{Plasma and urine AtIII}

In 57 normal males and females, plasma AtIII concentrations ranged from 145.0 to $250.0 \mathrm{mg} / \mathrm{l}$, with a mean of $198.8 \pm 24.7 \mathrm{mg} / \mathrm{l}($ mean $\pm \mathrm{SD})$. Diabetic patients without $(n=28)$ or with $(n=24)$ retinopathy have significantly higher concentrations $(219.0 \pm 24.3(\mathrm{p}<0.001)$ and $217.8 \pm 32.9 \mathrm{mg} / \mathrm{l}$ $(\mathrm{p}<0.01)$ respectively). In contrast, diabetics with nephropathy have values $(193.7 \pm 24.0 \mathrm{mg} / \mathrm{l})$ similar to those in normal subjects. The non- 

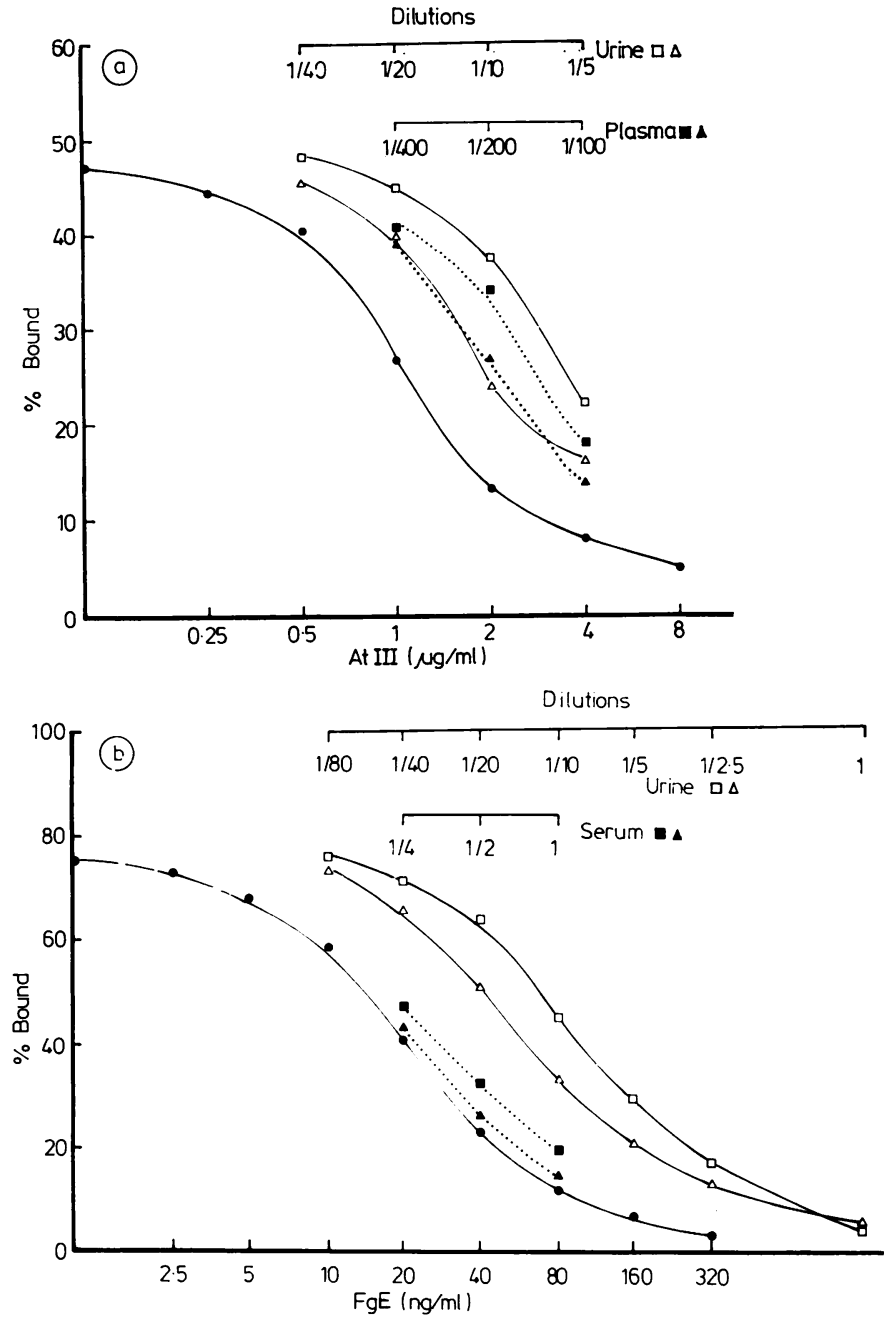

Fig. 1 (a) Doubling dilutions of two different plasma $(\square, \Delta)$ and urine $(\square, \triangle)$ samples showing parallel inhibitions with the AtIII standard curve (O).

(b) doubling dilutions of two different sera $(\square, \Delta)$ and urine $(\square, \triangle)$ samples showing parallel inhibitions with the FgE standard curve (O). diabetic patients with nephropathy also have normal values $(188.9 \pm 24.5 \mathrm{mg} / \mathrm{l})$.

In patients with diabetic nephropathy, the plasma AtIII was directly related to the total HbA $_{1}$ level $(r=0.3939, p=0.0488)$. However total $\mathrm{HbA}_{1}$ was not related to the degree of proteinuria or renal dysfunction. Whereas plasma AtIII was only inversely related to proteinuria $(\mathrm{r}=-0.3975$, $\mathrm{p}=0.0466$ ), urine AtIII was correlated directly to proteinuria $(\mathrm{r}=0.8065, \mathrm{p}<0.0001)$ and inversely to creatinine clearance $(\mathrm{r}=-0.4754, \mathrm{p}=0.0155)$ (Fig. 2). In addition, when matched for the same degree of proteinuria, diabetic patients with nephropathy have higher urine AtIII concentrations (Table) and on correlating proteinuria and urine AtIII, the regression slopes for both groups of patients were significantly different (Fig. 3), being greater in the diabetics.

Serum and urine $F g E$

In diabetics, serum FgE concentrations were raised, ranging from $50-100 \mathrm{ng} / \mathrm{ml}$ (normal range 10-30 $\mathrm{ng} / \mathrm{ml}$ ). Serum and urine $\mathrm{FgE}$ were directly related to each other $(r=0.8486, p<0.0001)$ and both inversely related to creatinine clearance $(r=-0.4475$, $\mathrm{p}=0.0235$ and $\mathrm{r}=-0.4701 \mathrm{p}=0.0169$ respectively). The amount of urine FgE excreted was also correlated to the urine protein excretion in both groups. However the diabetic patients excrete a larger amount of FgE in the urine (Table) and the regression line of urine $\mathrm{FgE}$ and proteinuria has a greater slope than that of the non-diabetics (Fig. 4). 


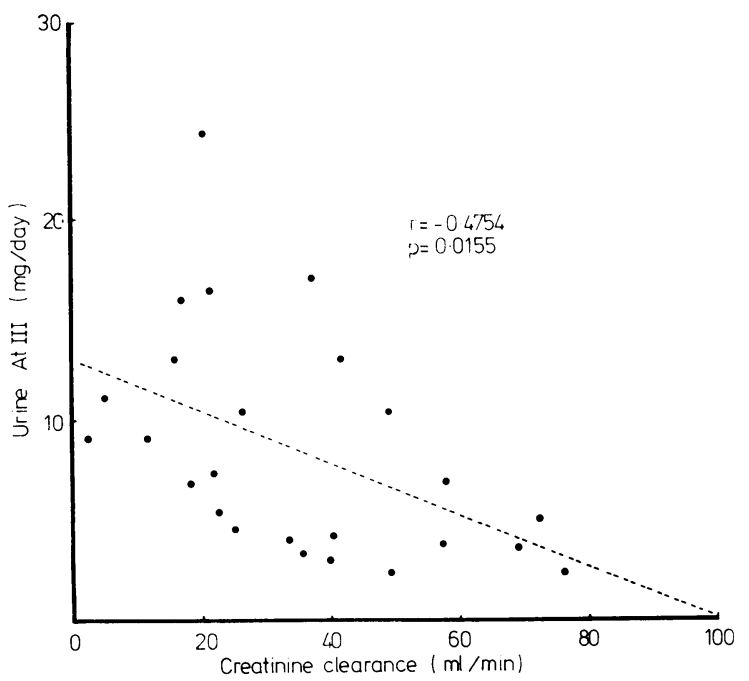

Fig. 2 Inverse relation between urine AtIII level and creatinine clearance in patients with diabetic nephropathy. The regression line is represented by (-----).

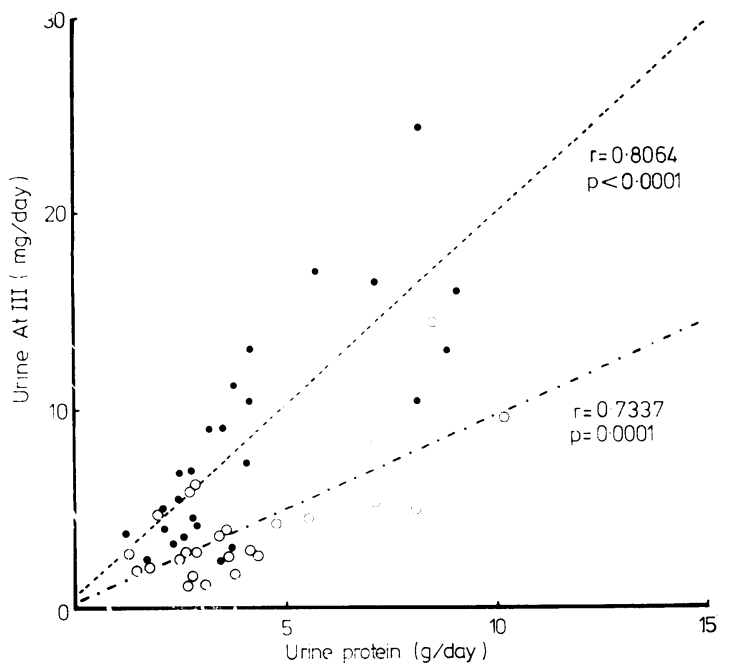

Fig. 3 Correlation between urine AtIII concentrations and proteinuria in diabetic $(\bigcirc)$ and non-diabetic $(\bigcirc)$ nephropathy. The slope of the regression line for the diabetics (----) was different from that of the non-diabetics $(-\cdot-\cdot-\cdot-\cdot)(\mathrm{t}=2 \cdot 85, p=0 \cdot 007)$.

\section{CIE of urine AtIII}

The CIE pattern of urine AtIII from a diabetic patient with nephropathy showed three peaks with the major portion in the two slower peaks, at equivalent position to the slower peaks present in serum (Fig. 5). This AtIII pattern is not an artefact

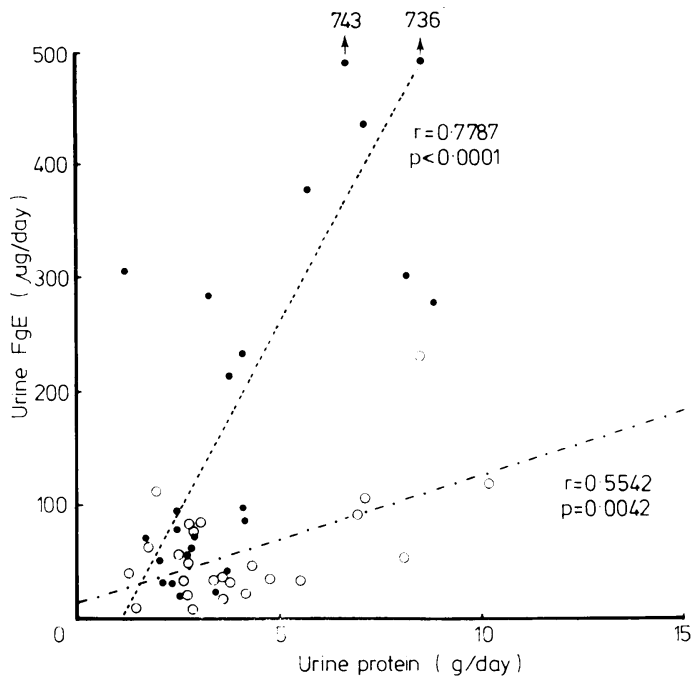

Fig. 4 Correlation between urine FgE concentrations and proteinuria in diabetic (O) and non-diabetic ( () nephropathy. The slope of the regression line for the diabetics (----) was different from that of the non-diabetics $(-\cdot-\cdot-\cdot-\cdot)(\mathrm{t}=4 \cdot 64, p<0 \cdot 001)$.

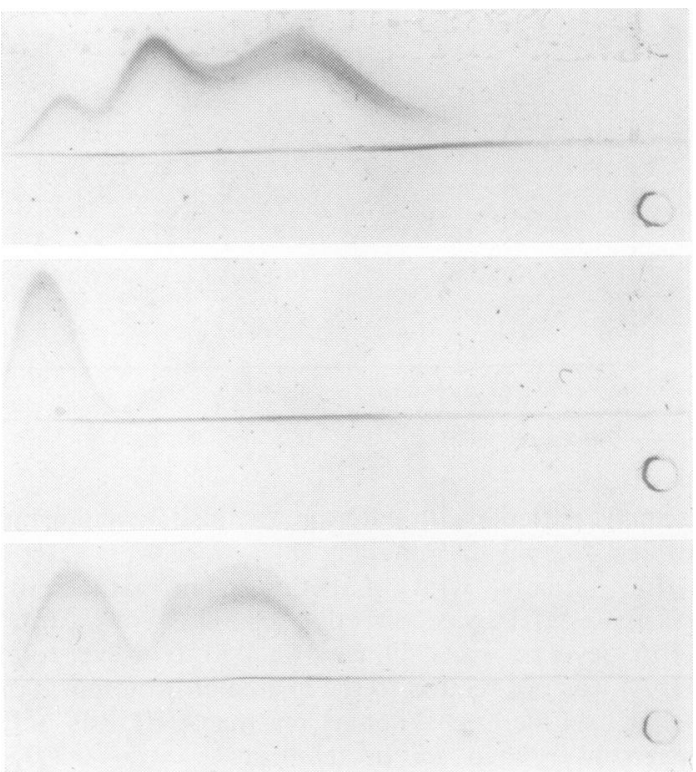

Fig. 5 Crossed immunoelectrophoretic pattern of samples run against antihuman AtIII serum. The first dimension was run in the presence of heparin $(16 \mathrm{U} / \mathrm{ml}$ gel) using $8 \mathrm{~V} / \mathrm{cm}$ for $45 \mathrm{~min}$ and the second dimension using $1.5 \mathrm{~V} / \mathrm{cm}$ for $16 \mathrm{~h}$. From top to bottom, the samples were (i) urine concentrate from a diabetic patient with nephropathy (ii) normal plasma added to urine from a control subject (iii) normal serum. 
of urine denaturation in vitro, since only single fast peak was obtained when plasma was added to normal urine and kept at room temperature for $24 \mathrm{~h}$ (Fig. 5, middle panel).

\section{Discussion}

Despite the fact that renal failure is a major cause of death in the diabetics, the correct treatment to prevent or delay the onset of diabetic nephropathy and to slow or arrest its progression is still unavailable. There is evidence that optimal glycaemic control may reduce the incidence of nephropathy in man $^{18}$ and normalisation of blood glucose in animals with experimentally induced diabetes had been shown to induce regression of their nephropathy. ${ }^{19}$ In the present study, the patients with diabetic nephropathy have increased total $\mathrm{HbA}_{1}$ concentration indicating inadequate glucose control and there was a positive correlation between total $\mathrm{HbA}_{1}$ and plasma AtIII. Furthermore, diabetic patients with or without retinopathy have higher AtIII concentrations than the controls. These findings suggest that poor diabetic control may be associated with a hypercoagulable state and increased plasma AtIII serves as a compensatory mechanism. There was also an increase in serum and urine $\mathrm{FgE}$ in patients with diabetic nephropathy, probably reflecting the deleterious effect of progressive intraglomerular fibrin deposition ${ }^{50}$ in this disease.

In this study, we have found that urinary AtIII as well as urine FgE are related directly to the degree of proteinuria. Also for the same degree of proteinuria, urine AtIII and FgEconcentrations were higher in the diabetics than in non-diabetic patients with nephropathy. This increased loss of AtIII and FgE could be explained by the "non-selective" pattern of protein loss in advance diabetic nephropathy. ${ }^{21} 22$ Alternatively, increased local concentration of AtIII and FgE due to intraglomerular thrombosis could result in their increased loss. The CIE pattern of urine AtIII showed marked increase in the slower peaks which represent AtIII-activated procoagulant complexes. ${ }^{14}$ This finding suggests that AtIII was bound to procoagulants before excretion and supports both the theories of increased local concentration resulting from thrombosis as well as the nonselective protein loss in the diabetics.

With progressive deterioration of renal function as indicated by decreasing creatinine clearance value, diabetic patients showed increasing urine AtIII and FgE losses. Although proteinuria per se also increased progressively, it showed a greater scatter and did not attain a significant inverse relation. Hence the monitoring of urine AtIII and FgE concentrations would provide additional parameters of the severity of renal damage and could be useful in assessing the progression of the disease. In addition, these would also reflect the hypercoagulable state in such patients and could be useful in monitoring the success of antithrombotic agents in arresting or reverting the diabetic nephropathy.

\section{References}

${ }^{1}$ Opperman W, Ehrenreich T, Bloodworth JMB, CameriniDavalos RA. Small-vessel disease in diabetes mellitus. In: Kryston LJ, Shaw RA, eds. Endocrinology and diabetes mellitus. New York: Grune \& Stratton, 1975: 427-42.

${ }^{2}$ Osterby R. Morphometric studies of the peripheral glomerular basement membrane thickening. Diabetologica 1972;8:84-92.

${ }^{3}$ Lee AKY, Chan V, Chan TK. The identification and localisation of antithrombin III in human tissues. Thromb Res 1979;14:209-17.

${ }^{4}$ Chan V, Chan TK. Antithrombin III in fresh and cultured human endothelial cells: a natural anticoagulant from the vascular endothelium. Thromb Res $1979 ; 15: 209-13$.

${ }^{5}$ Clarkson AR, McDonald MK, Petrie JJB, Cash JD, Robson JS. Serum and urinary fibrin/fibrinogen degradation products in glomerulonephritis. $\mathrm{Br}$ Med $\mathrm{J}$ $1971 ; 3: 447-51$.

${ }^{6}$ Farquhar A, McDonald MK, Ireland JT. The role of fibrin deposition in diabetic glomerulosclerosis: a light electron and immunofluorescence study. J Clin Pathol $1972 ; 251: 657-67$.

${ }^{7}$ Gellman DD, Pirani CC, Soothill JF, Muehrcke RC, Kark RM. Diabetic nephropathy. A clinical and pathologic study based on renal biopsies. Medicine (Baltimore) 1959;38:321-67.

${ }^{8}$ Watkins PJ, Blainey JD, Brewer DB et al. The natural history of diabetic renal disease: a follow-up study of a series of renal biopsies. $Q J$ Med $1972 ; 41: 437-54$.

${ }^{9}$ Takazakura E, Nakamoto Y, Hayakawa $\mathrm{H}$ et al. Onset and progression of diabetic glomerulosclerosis: a prospective study based on serial renal biopsies. Diabetes 1975;24:1-9.

10 Jones RH, Hayakawa H, Mackay JD, Parsons V, Watkins PJ. Progression of diabetic nephropathy. Lancet 1979; 1:1105-6.

11 Viberti GC, Keen H, MacKintosh D. Beta ${ }_{2}$-microglobulinaemia: a sensitive index of diminishing renal function in diabetics. Br Med J 1981;282:95-8.

${ }^{12}$ Chan V, Chan TK, Wong V, Tso SC, Todd D. The determination of antithrombin III by radioimmunoassay and its clinical application. Br J Haematol 1979; 41:563-72.

${ }^{13}$ Gordon YB, Martin MJ, Landon J, Chard T. The development of radioimmunoassay for fibrinogen degradation products: fragments D \& E. Br J Haematol 1975;29: 109-19.

${ }^{14}$ Chan TK, Chan V. The effect of venous occlusion on antithrombin III, plasminogen activator and fibrinogen degradation product (fragment E) levels. Thromb Res 1979;14:525-34.

${ }^{15}$ Lowry OH, Rosenbrough NJ, Fan AL, Randall RJ. Protein measurements with the folic phenol reagent. $J$ Biol Chem 1951;193:265-75.

${ }^{16}$ Gabbay K, Hasty K, Breslow JL, Ellison RC, Bunn HF, Gallop PM. Glycosylated haemoglobins and long term blood glucose control in diabetes mellitus. J Clin Endocrinol Metab 1977;44:859-64. 
17 Chan V, Chan TK. Heparin-antithrombin III binding: In vitro and in vivo studies. Haemostasis 1979;8:373-89.

18 Pirart J. Diabète et complications dègènèratives. Presentation d'une studie prospective portant sur 4400 cas observés entre 1947 et 1973. Diabete Metab 1977;3: 97-107, 173-82, 245-56.

19 Steffes MW, Maurer SM, Brown DM. The development, enhancement and reversal of the secondary complications of diabetes mellitus. Hum Pathol 1979;10: 293-9.

${ }^{20}$ Steihm ER, Trygstadt CW. Split products of fibrin in human renal disease. Am J Med 1969;46:774-86.
21 Jerums G, Post RS, Miller M, Barzellato E. Differential renal protein clearance in diabetes. Diabetes 1973; 22:104-10.

${ }^{22}$ Cameron JS, Ireland JT, Watkins PJ. In: Keen H, Jarrett $\mathrm{J}$, eds. Complications of diabetes. London: Edward Arnold, 1975:99-150.

Requests for reprints to: Dr Vivian Chan, Department of Medicine, University of Hong Kong, Queen Mary Hospital, Hong Kong.

\section{The May 1982 issue}

\section{THE MAY 1982 ISSUE CONTAINS THE FOLLOWING PAPERS}

Binding of serum ferritin to concanavalin $A$ in patients with iron overload and with chronic liver disease RWG CHAPMAN, A GORMAN, M LAULICHT, MAM HUSSAIN, SHEILA SHERLOCK, AV HOFFBRAND

Effect of ascorbic acid deficiency on serum ferritin concentration in patients with $\beta$-thalassaemia major and iron overload RWG CHAPMAN, MAM HUSSAIN, A GORMAN, M LAULICHT, DINA POLITIS, DM FLYNN, SHEILA SHERLOCK, AV HOFFBRAND

Ratio of blood and marrow-derived cells in bone marrow transplantation HEM KAY, HILARY LUMLEY, HMCD CLINK, RL POWLES

Distribution pattern of lysosomal granules in fibroblasts of the Chediak-Higashi syndrome $\mathrm{K}$ ABE, S ARASHIMA, M HONMA

Effect of total dose infusion of iron dextran on the storage iron content of the human placenta BB BAUMINGER, G WALTERS, JT WHICHER, AB DUKE

Elution of ${ }^{111}$ Indium from reticuloendothelial cells AM PETERS, I KLONIZAKIS, JP LAVENDER, SM LEWIS

Malignant histiocytosis of the intestine: report of three cases with immunological and cytochemical analysis P ISAACSON, DB JONES, MJ SWORN, DH WRIGHT

Studies of intestinal lymphoid tissue. IV - The predictive value of raised mitotic indices among jejunal epithelial lymphocytes in the diagnosis of gluten-sensitive enteropathy MN MARSH

Ovarian tumours of Wolffian or allied nature: their place in ovarian oncology PE HUGHESDON

Pathological evaluation of computed tomography images of lungs ROSEMARY CODDINGTON, SL MERA, PR GODDARD, JWB BRADFIELD
Primary biliary cirrhosis: an increased incidence of extrahepatic malignancies? PR MILLS, P BOYLE, EMM QUIGLEY, GG BIRNIE, F JARRETT, G WATKINSON, RNM MaCSWEEN

Significance of the site of origin of pancreatic exocrine adenocarcinoma TG ALLEN-MERSH

Comparison of the diagnostic value of serum pancreatic isomylase and immunoreactive trypsin measurement in patients with cystic fibrosis RC BROWN, DM CHALMERS, VL ROWE, J KELLEHER, JM LITTLEWOOD, MS LOSOWSKY

Comparison of culture and microscopy in the diagnosis of Gardnerella vaginalis infection CA ISON, SG DAWSON, J HILTON, GW CSONKA, CSF EASMON

A transport method for swab specimens submitted for aerobic and anaerobic bacteriology M ALFA, A LEE

Clostridium difficile and cytoxin in routine faecal specimens JQ NASH, B CHATTOPADHYAY, JOYCE HONEYCOMBE, SOAD TABAQCHALI

A simple, rapid ELISA method for the detection of DNA antibodies RP STOKES, A CORDWELL, RA THOMPSON

Technical methods

A celloidin bag for the histological preparation of cytologic material G BUSSOLATI

An improved method for sequential light and scanning electron microscopy of the same cell using localising microcoverslips KM SALEH, PG TONER, KE CARR, HE HUGHES

Letters to the Editor

Book reviews

Some new titles

Copies are still available and may be obtained from the PUBLISHING MANAGER, BRITISH MEDICAL ASSOCIATION, TAVISTOCK SQUARE, LONDON WC1H 9JR, price $£ 5.00$, including postage 